\title{
Harmonising Physis and Techne: The Mediating Role of Philosophy
}

\author{
Luciano Floridi
}

Published online: 27 January 2011

(C) Springer-Verlag 2011

An interesting way of looking at the history of cultures is in terms of the increasing distance of human life from the natural course of events, thanks to an everthickening layer of technological mediations. A culture (not necessarily a good culture, let alone a civilization) emerges when a society is able to detach itself from the physical world (physis), and generate sufficient resources to express itself with some stability. From the division of labour to sheer oppression, from the invention of tools to the creation of weapons, there must be at least a fissure between surviving and living, where the seeds of a culture can take root non-ephemerally. A culture therefore can be pre-historical (no recordings) but hardly pre-technological; "hardly" because, exceptionally, such breaking away from physis may be achievable by barehanded individuals in unaided contexts. In theory, nothing prevents extraordinary people from planting some cultural seeds even when life is flattened into survival twodimensionally, here and now. In practice, however, cultures tend to emerge and flourish only behind the dam provided by some techne. Even embittered stylites need pillars on which to stand, and peasants to bring food.

Once cultures are sufficiently advanced to be able to reflect critically on their technological conditions of possibility, they seem to encounter two traps.

One is the trap of nostalgia for some primordial authenticity. It leads a culture to believe that the future could improve if only there were no dam. Pristine nature, virgin phenomena and the humanly untouched are seen, from the safe distance afforded by techne itself and the accumulation of its benefits, as the regulative ideal one should at least aspire to implement. Physis appears as the promised land, lost because of techne, and hence progressively reclaimable only through the increasing removal of the latter. With a caricature: if only technology could be eradicated, our problems would be solved. Aristotle has a wonderful analogy that can be borrowed to chastise such illusion: it is as foolish as the dove's, which believed it could fly faster if there were no air.

L. Floridi $(\bowtie)$

Department of Philosophy, University of Hertfordshire, Hatfield, Hertfordshire, UK

e-mail: 1.floridi@herts.ac.uk 
The other trap is the hubris of ultimate power. In this case, a better future allegedly lies in ever smarter and more efficient uses of physis. The space on the other side of the dam is now seen as a reservoir of resources, which techne can appropriate and process more and more effectively. The other caricature in the diptych suggests that our problems would be solved if only we had more and better technologies. In this case, Hegel provides the insightful analogy which can be recycled to expose the mistake: the mastery culture foolishly fails to grasp that its increased technological reliance on the resources of the enslaved physis inevitably leads to the empowerment of the latter and its ultimate rebellion. Predictably, physis will take revenge, if the culture that exploits it is too careless.

In both cases, nostalgia or hubris, a lack of reflective discernment causes a seriously dangerous misunderstanding about the ecological relationship between physis and techne. Only together can they create the environment in which humanity may flourish. Ultimately, the equation is simple: culture requires resources, and resources are acquired and managed through technology. No techne, no resources, no culture. The question is not which side of the relation to drop or disregard, physis or techne, but rather how to negotiate the fine balance that can harmonise both.

Unfortunately, locating the traps and describing their nature are much easier than identifying the right course of action for the development of a successful marriage between physis and techne. Fortunately, it is exactly here that philosophy can help by exercising its mediating role, in the following sense.

The three-player game between physis, techne and philosophy can be complex, in the same way that chess is complex: not because of the basic rules, but because of the sophisticated ways in which they can be applied in a variety of circumstances full of implicit constraints, consequences and potential pitfalls. Indeed, the rules are trivial: avoid the two traps, nurture the right sort of physis (after all, we do wish to eradicate malaria once and for all, if possible), develop the right sort of techne, (e.g. renewable, non-polluting energy), and foster the right sort of culture. And all this thanks to the right sort of philosophy, which can enable us to make the right sort of moves that guarantee a harmonious and healthy decoupling of human history from natural events. The superficial simplicity of all these "the right sort" is misleading, as many examples of mistaken decisions and misdirected policies too often testify. The game is incredibly hard to master, not least politically and economically. And as if all this were not already bad enough, it is a game against the clock, in which time is running out, and one on which the future well-being of humanity is increasingly dependent. Nobody sufficiently informed can fail to feel a deep sense of urgency. This is why more philosophy is required, not less. We need to know the state of the game better, we need more discernment about the next promising moves, and we need more originality in envisioning the feasible strategies that may be successful. Analyses, syntheses, insights and intellectual creativity: this is how philosophy as conceptual engineering can help us to design a world in which, to use the previous metaphor, the marriage of physis and techne may be successful and bear fruit. We need to be stubbornly intellectual.

What I have sketched above is of course an enormous task, to which no contributing effort can be deemed too small. This is why, in presenting this first issue of Philosophy \& Technology, I wish to express a sense of hope and pride. Hope that the new journal will join and support the crucial effort of ensuring that our future 
will be better than our present, in the ecological sense outlined above. Pride in expecting that the journal will serve both the specialised community of researchers interested in the interactions between philosophies and technologies, and the wider community of all those keen on making techne and physis work together to mutual benefit.

The project is to publish articles that will engage with the conceptual investigation and the critical discussion of the challenges posed by technologies and their impact or implications. We intend to publish the best research produced in all areas where philosophy and technology meet. Good philosophy knows no cultural barriers or geographical borders, so the journal welcomes high-quality submissions, regardless of the tradition, school of thought or disciplinary background from which they derive. Any rigorous approach or methodology may be adopted: ethical, epistemological, philosophico-political, hermeneutic, analytic and so forth. And every area of technological innovation may be addressed, from new technologies in healthcare (e.g. e-Health), to nanotechnologies and their industrial development, from military technological applications to recent innovations in renewable energies, from transformations in transport systems to new information and communications technologies and developments in AI. Of course, investigations of cultural and conceptual issues are also most welcome, as well as efforts to address purely philosophical problems and topics from a technologically informed perspective. Ultimately, Philosophy \& Technology seeks to improve our critical understanding of the nature and practical consequences of technologies, and hence provide the foundation for their fruitful and sustainable developments.

Before closing this editorial introduction, I wish to thank all the staff at Springer, and in particular Marco Andal, Raul Boloron and Judy Pieren, for the outstanding work done in establishing and managing this new journal. Without Ties Nijssen, publishing editor at Springer, the project would have never been developed. His input and support have been extraordinary. There is something dreamlike about the two teams forming the executive editorial board and the scientific editorial board. Their quality could hardly find a match elsewhere, and I wish to thank them for their willingness to serve as members of each board. I have already relied heavily on their fine expertise, and I owe them more than I can express here. My debt is only going to increase.

Ultimately, the quality of a journal is only as high as the quality of the articles it publishes. So, my final word is to you reader. We at Philosophy \& Technology hope that you will find the journal interesting to read and worth your submissions. We look forward to your feedback and research. 